\title{
Does government spending crowd out voluntary labor and donations?
}

\section{There is little evidence that government spending crowds out private charitable donations of time and money}

Keywords: private philanthropy, time and money donations, government spending, crowding out

\section{ELEVATOR PITCH}

Private charitable contributions play an essential role in most economies. Despite the existence of welfare states, people contribute money and supply volunteer labor to charity. From a policy perspective, there is concern that comprehensive government spending might crowd out these private charitable donations. If perfect crowding out occurs, then every dollar spent by the government will lead to a one-for-one decrease in private spending, leaving the total level of welfare unaltered. Understanding the magnitude and causes of crowding out is crucial, as it represents a hidden cost to public spending and can thus have significant impacts on public welfare.

\section{KEY FINDINGS}

\section{Pros}

๑ If people are only concerned with the total level of welfare provided, they will treat government spending as a perfect substitute for their own donations.

- Crowding-out behavior is observed in laboratory experiments, which show that tax-financed contributions largely crowd out individuals' charitable contributions.

$\rightarrow$ Even if crowding out is small, potential negative consequences of a reduction in private philanthropy have to be considered.

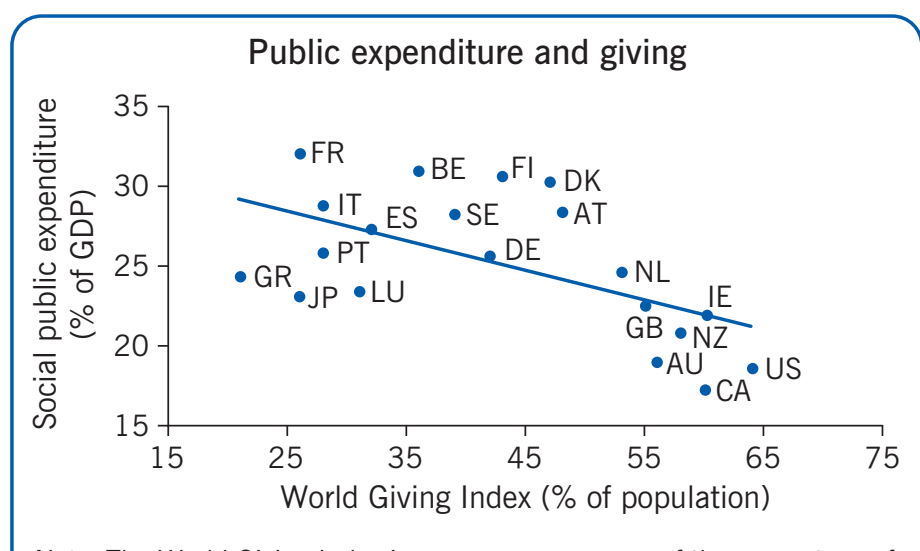

Note: The World Giving Index is an average measure of the percentage of people in each country who donate money, volunteer, or help a stranger. Source: Based on Figure 2.

I Z A $\int$

\section{Cons}

- The decision to contribute privately is determined by many other factors beyond the total level of welfare, such as the individual's desire for earning respect or social prestige, or the utility derived from the act of giving itself.

- Apart from the laboratory setting, there is hardly any empirical evidence to suggest that government spending largely crowds out individual charitable behavior.

- Studies based on micro-level data from charities as well as studies using regional or cross-country variation in private and public spending usually find small or incomplete crowding-out effects, or even some evidence of a crowding-in effect.

\section{AUTHOR'S MAIN MESSAGE}

The empirical evidence investigating whether public spending crowds out private charitable donations is mixed. A number of studies find significant but small crowding-out effects, while others find no effects or even evidence of a crowding-in effect. Hence, while crowding out might exist, it is far from being perfect. Policymakers should therefore acknowledge that their own expenditure on social welfare influences private spending. However, they should not be too concerned that an increase in government spending will largely crowd out private contributions of time and money. 


\section{MOTIVATION}

Private contributions of time and money play an essential role in most economies. Despite the existence of welfare states, people contribute money or volunteer labor for charities. However, little is known about why people decide to devote their time and money to charity. Closely linked to questions about the motives of pro-social behavior is the role of the welfare state in determining the level of private charitable contributions. If people are only concerned with the total amount of welfare provided, they should treat government spending as a substitute for their own donations. In such a situation, an increase (decrease) in government spending would result in a one-for-one decrease (increase) in private spending. This is referred to as perfect crowding out, and it has important policy implications. On the one hand, policymakers should be concerned that an increase in welfare spending will significantly lower the engagement of nonprofit organizations and private donors. On the other hand, it implies that the private sector will assume more of the responsibility for the provision of social services when the government decreases its level of welfare provision. If this holds true, public spending cuts could be justified based on the idea that the private sector takes over [1].

To prove the existence of a crowding-out effect, a comparison is often made between the US and Europe. The US, which is characterized by a low level of public welfare provision, is traditionally known for being one of the countries with the highest extent of charitable giving and volunteering worldwide. Europe, in contrast, is characterized by an extensive welfare state and a considerably lower private provision of charitable activities. Consequently, one might jump to the conclusion that extensive welfare states crowd out private charitable behavior. Whether this conclusion is justified, however, is a matter of debate.

\section{DISCUSSION OF PROS AND CONS}

\section{Determinants and cross-country variation of voluntary labor and donations}

There is not only a large difference in the role of charitable activities between the US and Europe, but also a high variation across individual countries. This is shown by the World Giving Index, a yearly survey conducted in 135 countries, which measures three different aspects of giving behavior: the percentage of people who, in a typical month, donate money to charity, volunteer time to an organization, or help a stranger. Based on information provided in the World Giving Index 2014, Figure 1 shows the percentage of individuals that donated money and volunteered time to a charity for a selected set of countries.

Figure 1 illustrates that countries with a high share of voluntary workers also tend to exhibit a relatively high share of charitable giving, suggesting a positive correlation between monetary and time donations (the correlation coefficient is 0.75 , where 1 indicates perfect correlation). All countries, except for Japan and Greece, show a higher proportion of individuals who donate money than who volunteer labor. Most importantly, however, is the large variation in charitable activities across countries. In particular, the AngloSaxon countries (Ireland, the UK, Canada, the US, Australia, and New Zealand) show the highest degree of charitable activity. Within the European countries, the Northern European countries rank highest, while the Southern European countries rank lowest. 
Figure 1. Labor and money donations in 2013

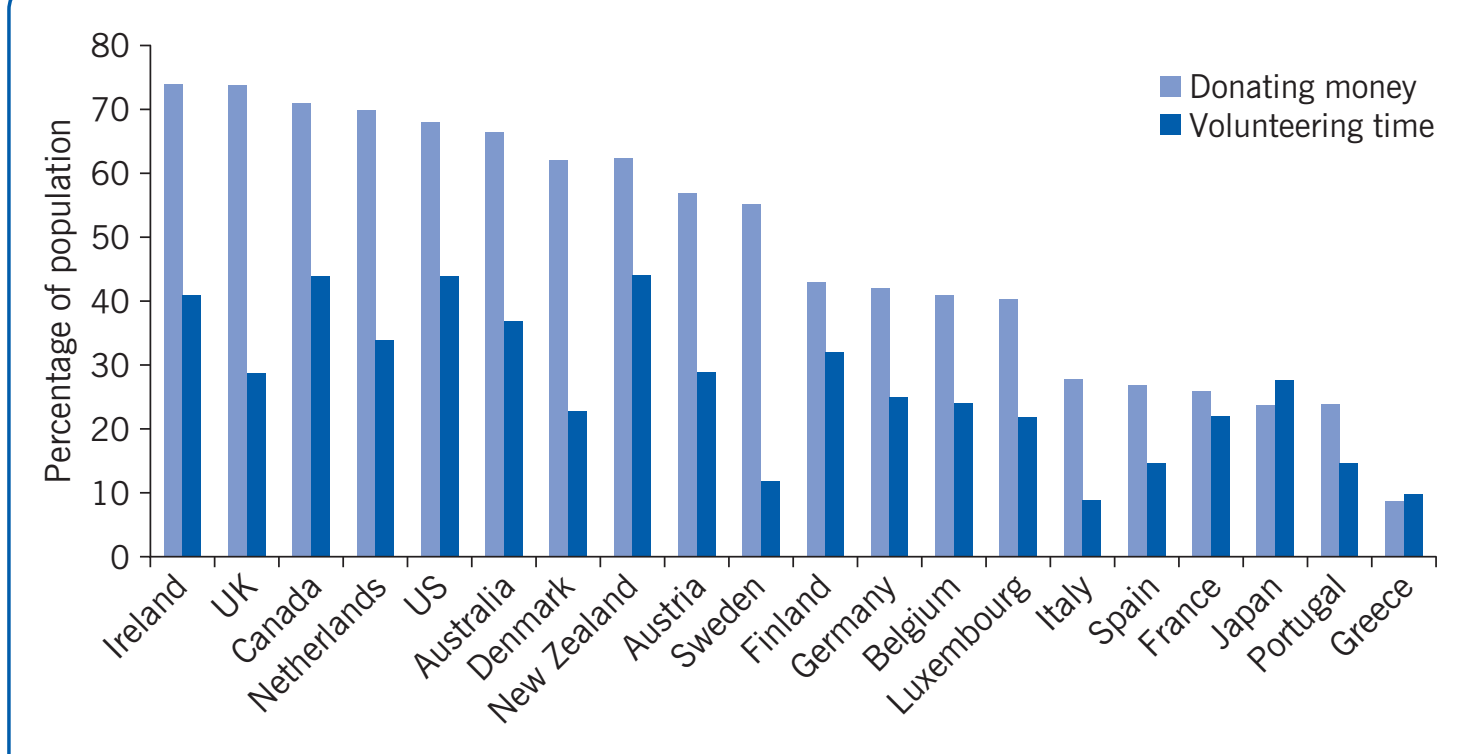

Source: World Giving Index 2014. Online at: https://www.cafonline.org/about-us/publications/world-giving-index-2014

Cross-country differences in voluntary donations could be partially explained by differences in the composition of the countries' populations [2]. And indeed, individual characteristics do play an important role in the decision to contribute to charity. Focusing on Europe, a recent study investigates the determinants of the individual decision to donate time or money using data from the 2002/2003 wave of the European Social Survey, which contains detailed information on individuals' voluntary activities in charitable organizations [2]. The study corroborates the assumption that volunteering is a normal good by finding a positive correlation between an individual's income and that person's probability of donating time and money to charity. It further shows that highly educated and older people are most likely to engage in charitable activities, while women and immigrants are less likely to donate time to charitable organizations. Moreover, religious people, as proxied by church membership, are more likely to donate time and money to charity. The authors also find differences in the individual determinants of charitable behavior across the European countries, in terms of educational attainment, gender, and immigration status. However, these individual differences alone are not sufficient in explaining the large variation in charitable activity across countries.

Another explanation for the cross-country variations in charitable activities could be that individuals in different countries face different environments and thus different incentives to contribute privately. In particular, people living in countries with an extensive welfare state that is financed by taxes may feel that the state already provides the needed services, so contribute less. Figure 2 supports this hypothesis, showing a simple correlation between the share of individuals contributing time and money to charity and government spending. For both money and time donations, there is a negative correlation between private and public contributions, suggesting that individuals treat government spending as a substitute for their own donations. However, while such a descriptive analysis suggests the existence of a crowding-out effect, both the theory and the empirical evidence on the crowding-out effect are rather inconclusive. 
Figure 2. Public expenditures, donations, and volunteering
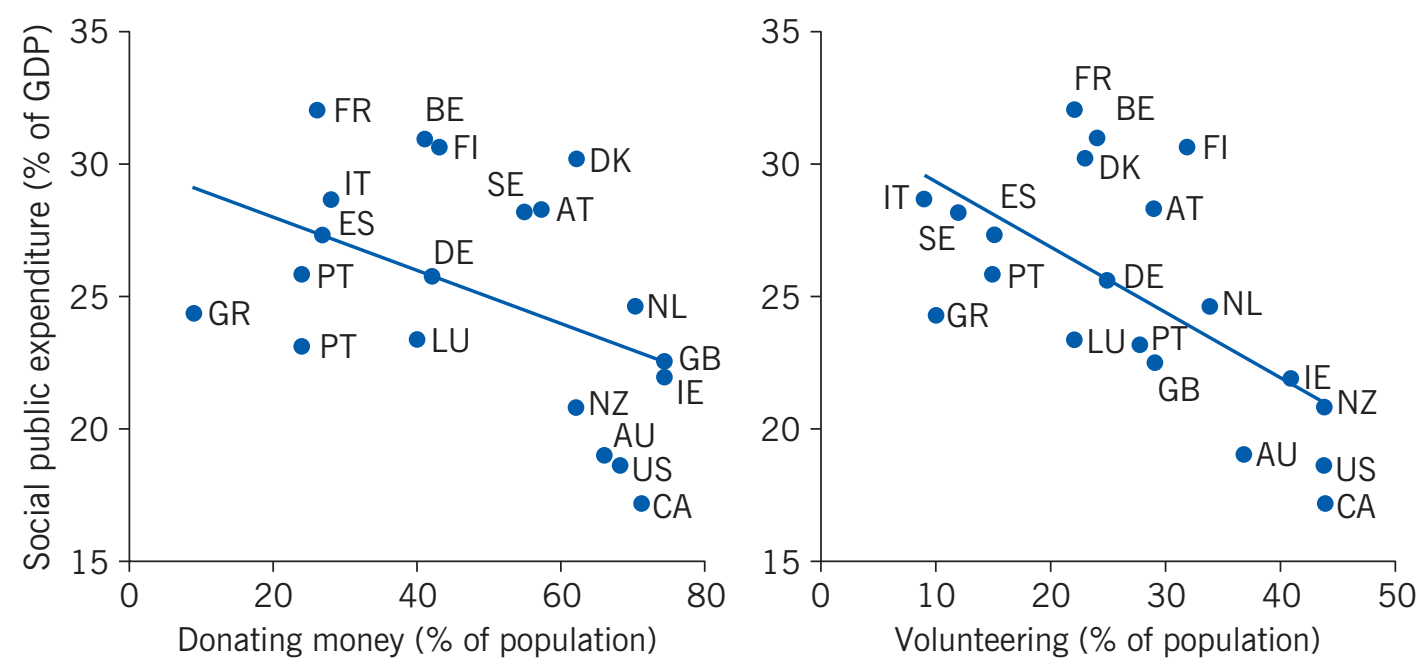

Source: World Giving Index 2014. Online at: https://www.cafonline.org/about-us/publications/2014-publications/worldgiving-index-2014; OECD Social Expenditure Database 2015. Online at: http://www.oecd.org/social/expenditure.htm

\section{Theoretical background: Crowding-out effect}

In order to determine whether government spending crowds out private philanthropy, it is important to determine what drives individuals to contribute time or money to charity. In economic models, pro-social behavior is often regarded as "altruism," which implies that there is no immediate gain for the individuals who contribute to charity. This raises the question of what motivates donors to give: the desire to increase the supply of a certain public good or the utility gain from the act of giving itself?

The traditional public good model of charitable giving suggests that individuals contribute to welfare provision because they are concerned with the utility of the recipients [3]. The donors are assumed to be "purely altruistic," meaning that they are only concerned with the total level of welfare, irrespective of the source of funding. Thus, they consider their contributions to be a perfect substitute for other private or public contributions. The model suggests that if the government provision of welfare increases, this would lead to a "dollar-for-dollar" or "one-for-one" adjustment in the donors' giving behavior, and the opposite is true for a decrease in public welfare provision. Therefore, if a public good is financed through private donations, a subsequent increase in government spending on the same public good would perfectly crowd out private donations.

So far, this theoretical model considers only monetary donations. However, the public good model can be extended, also taking into account time spent on charitable activities [4]. The extended model suggests that individuals view their contributions of money and time as perfect substitutes. In this framework, government spending will not only crowd out monetary donations, but also the supply of volunteer labor. As a result, empirical studies that ignore time contributions are incomplete, as they underestimate the true crowding-out effect.

Private charity donations, however, might not only be determined by altruism, but also by other personal characteristics like the individual's desire for earning respect, social 
prestige, or a "warm glow" feeling, which represent the individual's utility derived from the act of giving itself [5]. This motivation is called "impure altruism"; it implies that private donations have an altruistic component, which is the donor's concern about the total level of welfare, as well as an egoistic one, which is the personal utility gained from the act of donating. This is equivalent to assuming that contributions to charity are not a public good, but rather a private good. In this case, an increase in the government provision of a public good is not automatically followed by a one-for-one decrease in private contributions. An additional motive for altruism to be less than perfect is the individual desire to seek status or demonstrate wealth [6]. According to this argument, individuals give not only to increase the provision of the public good, but also to signal their income level or high status to other peer groups.

Another possibility is that larger government spending crowds in private donations because donors are not completely informed about the quality of a given charity. This is referred to as a signaling effect, where a large amount of government contributions acts as a signal of the charity's need and quality, which results in attracting additional private donors. In this case, increased government spending increases private contributions due to the positive signal given by the public sector. The signaling effect can also be extended to giving in general. This argument goes along with welfare regime theory, which suggests that public spending may have an influence on the donor's sense of obligation. A larger government contribution might induce people to donate privately because of a more persistent collective social concern [7].

\section{Empirical evidence: Crowding-out effect}

The theoretically predicted crowding-out effect is investigated in a number of empirical studies. This literature can be classified into three main strands: (i) studies using micro data at the charity level; (ii) studies using cross-country or regional variation to identify the crowding-out effect; and (iii) experimental studies [1].

\section{Evidence based on charity data}

Studies that are based on charity data are able to analyze different sources of revenue for each organization. In general, charity data provide information on the revenue generated from three main sources: autonomous income, private contributions, and government grants. Empirical studies using this type of data typically show a small degree of crowding out, or even a modest crowding in. In spite of the advantages of using charity data, some econometric issues need to be taken into account. Especially, the amount of public grants received by charities may be determined by unobserved factors that cannot be accounted for. For example, the charity's reputation could be correlated with both public and private contributions and not taking this into consideration would lead to biased estimates.

An example that addresses these issues is a study for the UK, which uses data from 178 charities for the period 1983-1990 to examine the crowding-out effect of government grants [8]. The authors consider a sample of charities with different main activities such as health, religion, and social welfare. The panel structure of the data allows them to capture unobserved, time-invariant institution-specific characteristics, e.g. the cause of the charity and the services provided. The results, however, may still be biased if changes in government donations are not determined exogenously, i.e. if there are time-varying 
unobserved factors that are correlated with both public and private contributions. The most common way to address this problem is to implement an instrumental variable approach. Using this technique, the results show that government grants do not crowd out, but rather crowd in voluntary donations, and that the crowding-in effect is even larger when government grants are instrumented. The crowding-in effect is explained by the fact that government grants serve as a signal of the charity's high quality, thus inducing private donors to contribute more to that specific charity.

A later study argues that the instrumental variables previously used-total government grants and deficit spending-are not valid [9]. The main reason is that both aggregate measures may alter private donations, not only through government grants, but also through other channels, such as the recipient's need or the donor's income level. Due to the lack of a convincing (alternative) instrument, this study does not address the endogeneity of government grants, yet the authors control for a number of factors that earlier literature neglected. The study uses panel data from 1986 to 1992 on private donations and government funding from the US to 125 international relief and development organizations. Besides taking into account charity fixed effects, the authors control for changes in beneficiaries' needs and for a possible inter-organization crowding-out effect between charities located in the same region and with similar objectives. The results show a negative relationship between government spending and private donations. The estimated effect, however, is small and not statistically significant in all specifications.

A larger crowding-out effect is found by a more recent study, which uses panel data for more than 8,000 US charities from 1985 to 2002 [10]. The authors estimates the magnitude of the crowding-out effect by taking into consideration a direct and an indirect effect. They argue that government grants could indirectly decrease voluntary giving because charities' efforts on fundraising are reduced. Thus, the estimated indirect crowding out refers to the donors' response to reduced fundraising activities, while direct crowding out refers to the donors' true response to increased public spending. The study addresses the endogeneity of both government grants and fundraising expenditures by using instrumental variables. To instrument government grants, variations in the tenure of congressional representatives from the Democratic and Republican parties are used. The idea is that congress members' power is correlated with the assignment of government grants, but is uncorrelated with private donations and charity expenditures for fundraising. The instruments considered for fundraising expenditures are the charity's total liabilities and occupancy expenses, which are related to its financial security. The authors argue that the charity's expenditures are correlated with its fundraising activities, but not with individuals' propensity to donate money or with government grants. The results show a very large crowding-out effect of about $73 \%$. However, this magnitude is fully attributable to the indirect effect of reduced fundraising. The direct effect shows a slightly positive response from the donors, which suggests a small crowding-in effect.

\section{Studies using regional or cross-country variation in public and private spending}

Several studies have analyzed the effect of the extent of the welfare state on charitable activity using regional or cross-country variation in public spending and private philanthropy. Although the crowding-out theory would suggest that a higher level of public spending induces people to volunteer less, these types of studies find very little empirical support for this assumption. 
Analyses of the crowding-out effect based on cross-country comparisons use either individual survey data on volunteering collected across different countries or aggregate data on the share of the population participating in charitable activities. These data are then correlated with measures of public welfare, such as public social expenditure. Analyses focus on voluntary labor supply and usually find hardly any evidence for a crowding-out effect; in some cases, they even present evidence for a crowding-in effect. However, these results might be biased because of the existence of time-invariant unobserved factors at the country level that are correlated with both social expenditure and volunteering rates, such as cultural or religious differences, or differences in wealth.

One exception to this is a recent study that combines individual data from the World Values Survey with macroeconomic data from the OECD [11]. The data cover 24 OECD countries for the period 1981-2000 and contain information on individual participation in voluntary work as well as on countries' public social expenditure as a percentage of GDP. In contrast to previous analyses, this study uses the panel structure of the data to address the problem of time-invariant unobserved heterogeneity at the country level, which might be correlated with both public and private contributions. The results show that an increase in public social expenditure significantly decreases the probability of volunteering, which suggests that government support lowers individuals' incentives to participate in volunteering activities.

Studies using aggregate data on public and private spending at a regional level, such as the state or province, also find hardly any evidence of a crowding-out effect. A recent study, for example, employs historical data from the UK during the 19th century [1]. The study uses data on a universal welfare spending program implemented to help the poor, and the income of private charities at the county level. Applying a simple regression technique, a pooled Ordinary Least Squares (OLS) model, the study finds a positive correlation between poor relief spending and charity giving. However, as this result might be driven by reverse causality, i.e. by a potential effect of private spending on public welfare provision, the authors further apply a difference-in-differences and an instrumental variable approach to identify a causal relationship between public and private giving. They use the distance from the county to London as an instrument to predict poor relief. The idea is that the distance from a county to London is exogenous, but that counties located closer to London provided a higher level of poor relief to keep laborers in their parish and avoid migration. While the instrument has the downside of lacking variation over time, the authors conduct several robustness checks to rule out that unobserved confounding factors at the county level still bias their results. The results of the instrumental variable approach are similar to those of the OLS model, namely that poor relief spending has a positive impact on charitable giving, suggesting that a more generous welfare state crowds in voluntary donations.

\section{Evidence based on laboratory experiments}

While the studies described above represent an indirect test of the motives underlying charitable behavior, experiments provide a way to more directly elicit information on individual preferences and motivations. Most economic laboratory experiments that test the crowding-out hypothesis implement extensions of the "dictator game." The dictator game is frequently used in behavioral economics when researchers are interested in the motivations that lead individuals to redistribute part of their income to others. The idea 
of the game is simple: one participant (dictator) is given a sum of money and has to decide how to distribute the money between him- or herself and another recipient.

One of the first laboratory experiments to test the crowding-out hypothesis implemented a version of the dictator game in order to distinguish between pure and impure altruism [7]. The participants, who were mainly university students, were randomly separated into two groups: dictators (group A) and recipients (group B). Each subject from group A was anonymously paired with one subject from group $B$. The participants playing role A were then asked to decide how they would like to distribute an initial allocation of money between themselves and the recipients, with the possibility of transferring $0-100 \%$ of their original endowment. The final payoff for $B$ would then be their respective initial endowment plus the contributions made by $A$. Two different treatments were implemented in order to test whether the initial distribution of money had an influence on individual contributions. In the first treatment, the dictator was given an initial endowment of $\$ 15$, while the recipient was given $\$ 5$. In the second treatment, the allocations were different, $\$ 18$ was given to the dictator and $\$ 2$ to the recipient. Perfect crowding out predicts that participants who were willing to give $\$ 3$ or more in the $\$ 18-\$ 2$ treatment would give $\$ 3$ less in the $\$ 15-\$ 5$ treatment, because only the final allocation matters. The results show that, conditional on giving, those with the lower initial endowment $(\$ 15-\$ 5)$ do give slightly less than those with the higher one (\$18-\$2). This rejects the perfect crowding-out hypothesis, and points towards an extensive but incomplete crowding-out effect.

One of the main downsides of the dictator study described in [7] is that the observed crowding out might not be accurately measured because contributions were given to a fellow student rather than to a person in need.

In a later study, this problem of unrealistic recipient characteristics is addressed by asking the subjects to allocate money between themselves and a charity of their choice [12]. In general, previous findings are supported by this study. However, the results also reveal a high sensitivity to how the experiment is framed. When the source of funding was not made apparent to the participants, the crowding-out effect was small. However, when the participants were told that the third-party support for the charity was financed through an explicit tax on their own endowment, private donations were perfectly crowded out.

Another laboratory experiment, which was designed to identify the magnitude of the "warm-glow" effect (i.e. when one receives positive personal feelings as a result of charitable giving), was implemented using a modified version of the dictator game [13]. The experiment was designed in such a way that a pure altruist would not have any incentive to participate. The subjects were given $\$ 10$, which they could distribute between themselves and a charity of their choice. The chosen charity would also receive money from an anonymous proctor. Any contribution made by the participants would substitute the contributions by the proctor, so that the amount of money the charity received would not be altered by the individual's contributions. The results show that, on average, participants gave about $20 \%$ of their original endowment to the charity, suggesting that there is indeed an egoistic motivation behind giving and that people benefit from the act of giving itself.

\section{LIMITATIONS AND GAPS}

While there exists a large literature analyzing whether government spending crowds out voluntary labor and donations, the empirical literature is not conclusive. This might be 
because the literature is missing a unified framework to test the crowding-out hypothesis. To date, studies have used a range of different approaches; as such, the results are hardly comparable.

The empirical literature generally uses information from charities or data from across countries or regions to analyze the relationship between private and public welfare spending. These studies often suffer from an omitted variable bias, i.e. the potential influence of unobserved factors at the charity or the country/regional level that are correlated with both public spending and private charitable contributions. While this issue is partly addressed by employing panel data or by exploiting some sort of exogenous variation in public spending in an instrumental variable approach, the literature would clearly benefit from more convincing identification strategies, such as natural experiments. Laboratory experiments overcome these empirical problems and thus represent a useful tool to test the effect of public on private spending, thereby providing helpful insights into the individual motivations behind private giving. However, due to the artificial settings, the extent to which the observed behavior can be generalized to the world outside the laboratory remains unclear.

Besides differences in underlying data and empirical approaches, studies also vary with respect to the charitable behavior considered. While most of the studies focus solely on monetary donations, cross-country comparisons focus solely on time donations, and only a few studies consider both. If money and time are substitutes (or complements), ignoring one or the other would lead to an underestimation (or overestimation) of the true crowding-out effect. Also, there is no clear definition of the type of charitable good considered. Some studies focus on giving to specific charities, such as health or social welfare organizations, while others consider charitable giving as a whole. In this context, it is also important to note that not all studies are able to perfectly match the reason for making private contributions with the definition of public expenditures. In other words, the purpose for both private and public contributions should be the same, e.g. public expenditures on poor relief should be matched with private donations to the same area. Instead, some studies use aggregate values for either public or private spending, thus violating the assumption that the two types of funding are perfect substitutes.

\section{SUMMARY AND POLICY ADVICE}

Although there exists a large literature investigating the role of government spending in determining private donations of time and money, the empirical evidence on the crowdingout effect is still mixed. Studies based on micro data on charities as well as cross-country studies usually find small crowding-out effects, while some even find evidence of a crowding-in effect. Laboratory experiments, in contrast, usually find evidence of large, though incomplete, crowding out. The conclusion that can be drawn from the literature is that crowding out exists, but that it is far from being perfect.

In conclusion, policymakers should acknowledge that public spending influences private spending. However, they should not be too concerned that an increase in government spending largely crowds out private contributions, nor can they count on the fact that a decrease in government spending is automatically compensated for by private giving. 


\section{Acknowledgments}

The author thanks an anonymous referee and the IZA World of Labor editors for many helpful suggestions on earlier drafts as well as Fernanda Martínez Flores for helpful research assistance. Financial support by the Fritz Thyssen Foundation is gratefully acknowledged.

\section{Competing interests}

The IZA World of Labor project is committed to the IZA Guiding Principles of Research Integrity. The author declares to have observed these principles.

(C) Julia Bredtmann 


\section{REFERENCES}

\section{Further reading}

Andreoni, J., and A. Payne. "Charitable giving." In: Auerbach, A. J., R. Chetty, M. Feldstein, and E. Saez (eds). Handbook of Public Economics. Volume 5. Amsterdam: Elsevier, 2013; pp. 1-50.

Schokkaert, E. "The empirical analysis of transfer motives." In: Kolm, S.-C., and J. M. Ythier (eds). Handbook of the Economics of Giving, Altruism and Reciprocity. Volume 1. Amsterdam: Elsevier, 2006; pp. 127-181.

\section{Key references}

[1] Boberg-Fazlic, N., and P. Sharp. "Does welfare spending crowd out charitable activity? Evidence from historical England under the poor laws." The Economic Journal (Forthcoming).

[2] Bauer, T., J. Bredtmann, and C. M. Schmidt. "Time vs. money: The supply of voluntary labor and charitable donations across Europe." European Journal of Political Economy 32 (2013): 80-94.

[3] Roberts, R. "A positive model of private charity and public transfers." Journal of Political Economy 92:1 (1984): 136-148.

[4] Duncan, B. "Modeling charitable contributions of time and money." Journal of Public Economics 72:2 (1999): 213-242.

[5] Andreoni, J. "Impure altruism and donations to public goods: A theory of warm-glow giving." The Economic Journal 100:401 (1990): 464-477.

[6] Glazer, A., and K. A. Konrad. "A signaling explanation for charity." American Economic Review 86:4 (1996): 1019-1028.

[7] Bolton, G., and E. Katok. "An experimental test of the crowding out hypothesis: The nature of beneficent behavior.” Journal of Economic Behavior \& Organization 37:3 (1998): 315-331.

[8] Khanna, J., and T. Sandler. "Partners in giving: The crowding-in effects of UK government grants.” European Economic Review 44:8 (2000): 1543-1556.

[9] Ribar, D., and M. Wilhelm. "Altruistic and joy-of-giving motivations in charitable behavior." Journal of Political Economy 110:2 (2002): 425-457.

[10] Andreoni, J., and A. A. Payne. "Is crowding out due entirely to fundraising? Evidence from a panel of charities." Journal of Public Economics 95:5-6 (2011): 334-343.

[11] Hackl, F., M. Halla, and G. J. Pruckner. "Volunteering and the state." Public Choice 151:3 (2010): 465-495.

[12] Eckel, C., P. Grossman, and R. Johnston. "An experimental test of the crowding out hypothesis.” Journal of Public Economics 89:8 (2005): 1543-1560.

[13] Crumpler, H., and P. Grossman. "An experimental test of warm glow giving." Journal of Public Economics 92:5 (2008): 1011-1021.

\section{Online extras}

The full reference list for this article is available from:

http://wol.iza.org/articles/does-government-spending-crowd-out-voluntary-labor-anddonations

View the evidence map for this article:

http://wol.iza.org/articles/does-government-spending-crowd-out-voluntary-labor-anddonations/map 